\title{
Article \\ Salmonella spp. in Pet Reptiles in Portugal: Prevalence and Chlorhexidine Gluconate Antimicrobial Efficacy
}

\author{
João B. Cota *D, Ana C. Carvalho, Inês Dias, Ana Reisinho, Fernando Bernardo and Manuela Oliveira \\ CIISA-Centro de Investigação Interdisciplinar em Sanidade Animal, Faculdade de Medicina Veterinária, \\ Universidade de Lisboa, Av. da Universidade Técnica, 1300-477 Lisboa, Portugal; \\ accarvalho@fmv.ulisboa.pt (A.C.C.); ines.adpdias@gmail.com (I.D.); anareisinho@fmv.ulisboa.pt (A.R.); \\ fbernardo@fmv.ulisboa.pt (F.B.); moliveira@fmv.ulisboa.pt (M.O.) \\ * Correspondence: joaobcota@fmv.ulisboa.pt; Tel.: +351-213-652-800
}

Citation: Cota, J.B.; Carvalho, A.C.; Dias, I.; Reisinho, A.; Bernardo, F.; Oliveira, M. Salmonella spp. in Pet Reptiles in Portugal: Prevalence and Chlorhexidine Gluconate Antimicrobial Efficacy. Antibiotics 2021, 10, 324. https://doi.org/ 10.3390/antibiotics 10030324

Academic Editor: Jonathan Frye

Received: 27 February 2021

Accepted: 17 March 2021

Published: 19 March 2021

Publisher's Note: MDPI stays neutral with regard to jurisdictional claims in published maps and institutional affiliations.

Copyright: (c) 2021 by the authors. Licensee MDPI, Basel, Switzerland. This article is an open access article distributed under the terms and conditions of the Creative Commons Attribution (CC BY) license (https:// creativecommons.org/licenses/by/ $4.0 /)$.

\begin{abstract}
A fraction of human Salmonella infections is associated with direct contact with reptiles, yet the number of reptile-associated Salmonellosis cases are believed to be underestimated. Existing data on Salmonella spp. transmission by reptiles in Portugal is extremely scarce. The aim of the present work was to evaluate the prevalence of Salmonella spp. in pet reptiles (snakes, turtles, and lizards), as well as evaluate the isolates' antimicrobial resistance and virulence profiles, including their ability to form biofilm in the air-liquid interface. Additionally, the antimicrobial effect of chlorhexidine gluconate on the isolates was tested. Salmonella was isolated in $41 \%$ of the animals sampled and isolates revealed low levels of antimicrobial resistance. Hemolytic and lypolytic phenotypes were detected in all isolates. The majority (90.63\%) of the Salmonella isolates were positive for the formation of pellicle in the air-liquid interface. Results indicate chlorhexidine gluconate is an effective antimicrobial agent, against the isolates in both their planktonic and biofilm forms, demonstrating a bactericidal effect in $84.37 \%$ of the Salmonella isolates. This study highlights the possible role of pet reptiles in the transmission of non-typhoidal Salmonella to humans, a serious and increasingly relevant route of exposure in the Salmonella public health framework.
\end{abstract}

Keywords: Salmonella; reptiles; isolation; antimicrobial resistance; biofilms; chlorhexidine gluconate; public health

\section{Introduction}

Salmonella is a well-known food-borne illness etiological agent, reported as the second most common zoonotic agent, causing 91,857 confirmed cases of disease in the European Union during 2018 [1] and an estimated number of 93.8 million cases worldwide annually [2]. The clinical manifestations of human salmonellosis are frequently those associated with a self-limited gastroenteritis, namely nausea, vomiting and diarrhea, but can also include severe complications, including bacteremia and extra-intestinal infections [3]. Though most commonly associated with contaminated food, human salmonellosis can also occur through the contact with infected animals, such as farm animals and pets, including reptiles [4].

In the course of the past years, reptiles have been increasingly regarded as household pets, with their estimated numbers ascending up to 8 million only in the Europe Union in 2019 [5]. Salmonella not only can be found in the gastrointestinal tract of healthy reptiles, but also in the environments where those animals are kept [6,7]. Salmonella enterica subspecies enterica is commonly found in warm-blooded animals, while the remainder subspecies, salamae, arizonae, diarizonae, houtenae, and indica, along with Salmonella bongori are frequently isolated either from reptiles or from the environment [8]. Furthermore, among more than 2500 known Salmonella serotypes, over 40\% are associated with reptiles and are rarely isolated from other animals, including humans [9]. Although infrequent when compared with food-borne cases, accounting for $6 \%$ of all human salmonellosis cases both in the 
USA and in Europe [10], reptile-associated salmonellosis (RAS) seems to be more related with more severe clinical scenarios, such as systemic and severe disease development, especially in children, elderly people, and pregnant women [6]. In fact, RAS is a growing public health concern worldwide, with different reports pointing out for its role in disease outbreaks $[11,12]$. Despite the several RAS cases that have been reported in different European countries [13], there seems to be no available data regarding Portugal.

As observed for non-typhoidal salmonellae of other sources, there has been an increasing focus on antimicrobial resistance in reptile-associated Salmonella [14-16] since this feature can impair the success of treatments of both human and veterinary Salmonella infections [17]. Antimicrobial resistance can either arise from mutations in chromosomal genes (intrinsic resistance), which are caused by selective pressure, or through the acquisition of antimicrobial resistance determinants encoded in plasmids (extrinsic resistance), by horizontal transfer [18]. The role of reptiles as disseminators of antimicrobial resistant (AMR) Salmonella has been suggested $[19,20]$. Furthermore, Salmonella is known to have the ability of producing biofilms in different biotic and abiotic surfaces [21]. Not only are bacterial cells in biofilms more tolerant to antimicrobials when compared with the corresponding planktonic cells [22] but also more resistant to several chemical disinfectants [21].

Chlorhexidine is a biocide widely included in antiseptic products, especially in handwashing and oral products, due to its broad-spectrum efficacy and low irritability [23]. For surgical skin preparations and hand scrub, chlorhexidine is available in $4 \%$ solutions, while for wound cleaning is used as a $0.5 \%$ concentrated solution [24]. In veterinary care, chlorhexidine gluconate is a common disinfectant. In reptile treatment, chlorhexidine solutions are frequently used for topical application and preoperative scrubs, in concentrations below $2 \%$ [25], but there is a lack of clear guidelines regarding the most appropriate concentration to use.

The aim of the present study was to assess the presence of Salmonella spp. among the intestinal microbiota of pet reptiles in the Metropolitan area of Lisbon, Portugal, and to characterize those isolates, regarding antimicrobial susceptibility and virulence traits, bringing more information on the role of reptile-associated Salmonella on the public health scenario. Additionally, the antimicrobial efficacy of chlorhexidine gluconate against both planktonic cells and biofilms was also evaluated.

\section{Results}

\subsection{Salmonella spp. Isolates}

Of the 78 reptiles sampled 32 were identified as Salmonella positive (41\%), specifically four Ophidians (50\%), 14 Saurians (51.9\%), and nine Chelonians (20.9\%), belonging to 12 different owners (Table 1). Overall, the Salmonella recovery rates where higher both in Ophidians and Saurians when comparing with the one recorded in Chelonians $(p=0.016)$. After assessing the biochemical profile using API20E strip tests of the presumptive Salmonella isolates, 13 were identified as Salmonella enterica subspecies arizonae and 19 as Salmonella spp. (Table 2).

More than half of all Salmonella positive animals (62.5\%) were detained by only three owners (E, F, and J). Moreover, owner J alone kept 12 Salmonella positive reptiles, more specifically Saurians. Salmonella isolates from co-habiting animals belonged to similar species with the exception for the isolates recovered from the animals of owner J, where the majority was identified as Salmonella enterica subspecies arizonae (10/12) and the remaining as Salmonella spp. (2/12) (Table 2). Notably, whenever an owner possessed multiple Salmonella positive animals, those animals belonged to the same reptile group. 
Table 1. Salmonella positive animals, divided by category and species.

\begin{tabular}{ccc}
\hline Category & Species & Number of Positive Animals \\
\hline Ophidians & Pantherophis guttatus guttatus & 2 \\
& Python regius & 2 \\
Chelonians & Chelonoidis carbonaria & 1 \\
& Geochelone sulcata & 1 \\
& Pseudemys spp. & 1 \\
& Sternotherus odoratus & 2 \\
Testudo horsfield & 1 \\
& Traquemys scripta elegans & 1 \\
Chlamydosaurus kingii & 2 \\
Ctenosaura quinquecarinata & 2 \\
Gerrhosaurus major & 1 \\
& Hydrosaurus amboinensis & 1 \\
& Iguana iguana & 1 \\
& Physignatus cocincinus & 1 \\
& Physignatus lesueurii lesueurii & 3 \\
Pogona vitticeps & 1 \\
Tupinambis rufrescens & 8 \\
&
\end{tabular}

Table 2. Detailed information regarding the Salmonella isolates under study.

\begin{tabular}{|c|c|c|c|c|}
\hline Isolate Number & Group & Species & Owner & API20E Result \\
\hline 4 & Ophidian & Python regius & A & Salmonella enterica subsp. arizonae \\
\hline 12 & Chelonian & Pseudemys spp. & $\mathrm{B}$ & Salmonella spp. \\
\hline 21 & Ophidian & Pantherophis guttatus guttatus & $\mathrm{C}$ & Salmonella spp. \\
\hline 26 & Chelonian & Geochelone sulcata & $\mathrm{D}$ & Salmonella enterica subsp. arizonae \\
\hline 27 & Chelonian & Chelonoidis carbonaria & $\mathrm{D}$ & Salmonella enterica subsp. arizonae \\
\hline 30 & Saurian & Pogona vitticeps & $\mathrm{E}$ & Salmonella spp. \\
\hline 31 & Saurian & Pogona vitticeps & $\mathrm{E}$ & Salmonella spp. \\
\hline 32 & Saurian & Pogona vitticeps & $\mathrm{E}$ & Salmonella spp. \\
\hline 33 & Saurian & Physignatus cocincinus & $\mathrm{E}$ & Salmonella spp. \\
\hline 34 & Saurian & Pogona vitticeps & $\mathrm{E}$ & Salmonella spp. \\
\hline 35 & Chelonian & Centrochelys sulcata & $\mathrm{F}$ & Salmonella spp. \\
\hline 36 & Chelonian & Testudo horsfield & $\mathrm{F}$ & Salmonella spp. \\
\hline 41 & Chelonian & Sternotherus odoratus & $\mathrm{F}$ & Salmonella spp. \\
\hline 44 & Chelonian & Pseudemys spp. & $\mathrm{G}$ & Salmonella spp. \\
\hline 46 & Saurian & Pogona vitticeps & $\mathrm{H}$ & Salmonella spp. \\
\hline 47 & Chelonian & Traquemys scripta elegans & $\mathrm{I}$ & Salmonella enterica subsp. arizonae \\
\hline 48 & Chelonian & Traquemys scripta elegans & I & Salmonella spp. \\
\hline 50 & Saurian & Ctenosaura quinquecarinata & $\mathrm{J}$ & Salmonella enterica subsp. arizonae \\
\hline 52 & Saurian & Physignatus cocincinus & $\mathrm{J}$ & Salmonella enterica subsp. arizonae \\
\hline 53 & Saurian & Physignatus cocincinus & $\mathrm{J}$ & Salmonella einterica subsp. arizonae \\
\hline 54 & Saurian & Tupinambis rufrescens & $\mathrm{J}$ & Salmonella enterica subsp. arizonae \\
\hline 55 & Saurian & Pogona vitticeps & $\mathrm{J}$ & Salmonella spp. \\
\hline 56 & Saurian & Pogona vitticeps & $\mathrm{J}$ & Salmonella enterica subsp. arizonae \\
\hline 58 & Saurian & Gerrhosaurus major & $\mathrm{J}$ & Salmonella enterica subsp. arizonae \\
\hline 61 & Saurian & Hydrosaurus amboinensis & $\mathrm{J}$ & Salmonella enterica subsp. arizonae \\
\hline 62 & Saurian & Chlamydosaurus kingii & $\mathrm{J}$ & Salmonella enterica subsp. arizonae \\
\hline 63 & Saurian & Chlamydosaurus kingii & $\mathrm{J}$ & Salmonella spp. \\
\hline 66 & Saurian & Physignatus lesueurii lesueurii & $\mathrm{J}$ & Salmonella enterica subsp. arizonae \\
\hline 69 & Saurian & Iguana iguana & $\mathrm{J}$ & Salmonella enterica subsp. arizonae \\
\hline 70 & Ophidian & Pyton regius & $\mathrm{K}$ & Salmonella enterica subsp. arizonae \\
\hline 73 & Ophidian & Pantherophis guttatus guttatus & $\mathrm{K}$ & Salmonella spp. \\
\hline 76 & Saurian & Pogona vitticeps & $\mathrm{L}$ & Salmonella spp. \\
\hline
\end{tabular}




\subsection{Antimicrobial Resistance}

All of the studied isolates were susceptible to gentamicin $(\mathrm{CN})$ and ciprofloxacin (CIP) (Table 3). High levels of susceptibility to amikacin (AK) $(96.87 \%)$, sulfamethoxazole/trimethoprim (SXT) (96.87\%), nalidixic acid (NA) (93.75\%), enrofloxacin (ENR) (90.63\%), amoxicillin/clavulanic acid (AMC) (90.63\%), ampicillin (AMP) (90.63\%), cefotaxime (CTX) (87.50\%), tetracycline (TE) $(87.50 \%)$, and to chloramphenicol (C) $(81.25 \%)$ were also recorded. On the other hand, 31 of the Salmonella isolates $(96.87 \%)$ were resistant to penicillin $(\mathrm{P})$.

Table 3. Antimicrobial resistance and virulence phenotype results.

\begin{tabular}{|c|c|c|c|c|}
\hline Antimicrobial Resistance & Ophidians (\%) & Chelonians (\%) & Saurians (\%) & $p$ Value \\
\hline AMC & $0(0 \%)$ & $3(33.3 \%)$ & $0(0 \%)$ & 0.0286 \\
\hline AMP & $0(0 \%)$ & $3(33.3 \%)$ & $0(0 \%)$ & 0.0286 \\
\hline AK & $0(0 \%)$ & $1(11.1 \%)$ & $0(0 \%)$ & N.S. \\
\hline $\mathrm{C}$ & $0(0 \%)$ & $0(0 \%)$ & $1(5.26 \%)$ & N.S. \\
\hline $\mathrm{CN}$ & $0(0 \%)$ & $0(0 \%)$ & $0(0 \%)$ & - \\
\hline CTX & $0(0 \%)$ & $0(0 \%)$ & $0(0 \%)$ & - \\
\hline ENR & $0(0 \%)$ & $0(0 \%)$ & $0(0 \%)$ & - \\
\hline NA & $0(0 \%)$ & $1(11.1 \%)$ & $1(5.26 \%)$ & N.S. \\
\hline $\mathbf{P}$ & $4(100 \%)$ & $8(88.89 \%)$ & $19(100 \%)$ & N.S. \\
\hline CIP & $0(0 \%)$ & $0(0 \%)$ & $0(0 \%)$ & - \\
\hline SXT & $0(0 \%)$ & $0(0 \%)$ & $1(5.26 \%)$ & N.S. \\
\hline TE & $0(0 \%)$ & $1(11.1 \%)$ & $0(0 \%)$ & N.S. \\
\hline \multicolumn{5}{|l|}{ Virulence phenotype } \\
\hline Hemolytic activity & $4(100 \%)$ & $9(100 \%)$ & $19(100 \%)$ & - \\
\hline Lipolytic activity & $4(100 \%)$ & $9(100 \%)$ & $19(100 \%)$ & - \\
\hline DNase activity & $4(100 \%)$ & $4(44.44 \%)$ & $11(57.89 \%)$ & N.S. \\
\hline Gelatinolytic activity & $0(0 \%)$ & $0(0 \%)$ & $0(0 \%)$ & - \\
\hline
\end{tabular}

Abbreviations: AMC, amoxicillin/clavulanic acid; AMP, ampicillin; AK, amikacin; C, chloramphenicol; CN gentamicin; CTX, cefotaxime; ENR, enrofloxacin; NA, nalidixic acid; P, penicillin; CIP, ciprofloxacin; SXT, sulfamethoxazole/trimethoprim; TE, tetracycline; N.S., non-significant.

When comparing groups, resistance to AMC $(p=0.0286)$ and AMP $(p=0.0286)$ were associated with Chelonian Salmonella spp. isolates, as resistance to both antimicrobials was only detected, and simultaneously, in isolates 26,36 , and 47 , all originating from turtles of different owners (Supplementary Table S1). No other statistically significant differences regarding antimicrobial susceptibility were detected.

Only three isolates $(9.37 \%)$, all from Chelonians, were resistant to three or more of the antimicrobial compounds tested (isolates 26, 36, and 47) (Supplementary Table S1). The multiple resistance patterns were AMC/AMP/P, observed in isolates 26 and 36 , and $\mathrm{AMC} / \mathrm{AMP} / \mathrm{P} / \mathrm{TE}$, revealed by isolate 47 . None of the isolates was considered to be multidrug resistant, since the detected resistance patterns included antibiotics from the same class.

\subsection{Virulence Phenotype}

Virulence phenotypic testing revealed that all of the isolates studied expressed both hemolytic and lipolytic behaviors (Table 3). Contrarily, gelatinase activity was not detected in any of the Salmonella isolates studied. Overall, DNase activity was observed in more than half $(59.37 \%)$ of the isolates. No statistically significant differences in phenotypical behavior were identified when comparing isolates from different animal groups.

\subsection{Minimum Inhibitory Concentration and Minimum Bactericidal Concentration}

The minimum inhibitory concentration (MIC) and minimum bactericidal concentration (MBC) values of chlorhexidine gluconate calculated for each isolate can be found on Supplementary Table S1.

The overall average MIC value was $11.90 \mathrm{mg} / \mathrm{L} \pm 3.68$, ranging from $8.16 \mathrm{mg} / \mathrm{L}$ (MIC value observed towards a Chelonian isolate), to $23.81 \mathrm{mg} / \mathrm{L}$ (MIC value towards 
a Chelonian and a Saurian isolates, all from different owners), with a median value of $10.72 \mathrm{mg} / \mathrm{L}$. The majority of the chlorhexidine gluconate MIC values (75\%) calculated for each Salmonella isolate only ranged between $9.52 \mathrm{mg} / \mathrm{L}$ and $14.29 \mathrm{mg} / \mathrm{L}$. When comparing groups, the average MIC values regarding Ophidian, Chelonian, and Saurian isolates were $11.98,11.25$, and $12.19 \mathrm{mg} / \mathrm{L}$, respectively, the differences were not statistically significant $(p=0.802)$ (Table 4$)$.

Table 4. Chlorhexidine gluconate minimum inhibitory concentrations, minimum bactericidal concentrations, minimum biofilm inhibitory concentrations, minimum biofilm eradication concentrations and biofilm formation results.

\begin{tabular}{ccccc}
\hline Heading & Ophidians & Chelonians & Saurians & $p$ Value \\
\hline MIC $(\mathbf{m g} / \mathbf{L})$ & $11.98 \pm 1.46$ & $11.25 \pm 4.66$ & $12.19 \pm 3.44$ & N.S. \\
MBC $(\mathbf{m g} / \mathbf{L})$ & $86.84 \pm 72.75$ & $27.87 \pm 11.71$ & $33.87 \pm 52.91$ & N.S. \\
MBIC $(\mathbf{m g} / \mathrm{L})$ & $57.15 \pm 28.57$ & $64.02 \pm 12.32$ & $72.87 \pm 39.60$ & N.S. \\
MBEC (mg/L) & $244.05 \pm 131.49 *$ & $333.65 \pm 222.2 *$ & $397.39 \pm 194.74 *$ & N.S. \\
Biofilm formation (days) & $5.1 \pm 0.49$ & $4.7 \pm 1.0$ & $4.2 \pm 0.79$ & N.S. \\
\hline
\end{tabular}

Abbreviations: MIC, minimum inhibitory concentration; MBC, minimum bactericidal concentration; MBIC, minimum biofilm inhibitory concentration; MBEC, minimum biofilm eradication concentration; N.S., nonsignificant. * Values above $714.29 \mathrm{mg} / \mathrm{L}$ were not included.

Regarding MBC, the overall mean value was $38.8 \mathrm{mg} / \mathrm{L} \pm 50.25$, with a minimum value of $9.52 \mathrm{mg} / \mathrm{L}$ (observed towards a Chelonian isolate), and a maximum value of $247.62 \mathrm{mg} / \mathrm{L}$ (regarding a Saurian isolate), with a median value of $23.22 \mathrm{mg} / \mathrm{L}$. Although a high variability in MBC values was found, towards half of the studied isolates those values ranged between $11.91 \mathrm{mg} / \mathrm{L}$ and $23.81 \mathrm{mg} / \mathrm{L}$. When comparing groups, the average MBC values obtained regarding the Ophidian isolates, $86.84 \mathrm{mg} / \mathrm{L}$, the Chelonian isolates, $27.87 \mathrm{mg} / \mathrm{L}$ and the Saurian isolates, $33.87 \mathrm{mg} / \mathrm{L}$, were not statistically different $(p=0.257)$.

Chlorhexidine gluconate demonstrated to have a bactericidal effect in the majority of the Salmonella isolates (84.37\%), since only five isolates (15.63\%) had MBC/MIC ratio above 4 (Supplementary Table S1).

\subsection{Biofilm Formation in the Air-Liquid Interface}

The biofilm formation capability of the Salmonella isolates obtained from pet reptiles was studied by observing the development of a pellicle in the air-liquid interface. Of all isolates, only three (9.37\%) were not able to form biofilms, thus the vast majority $(90.63 \%)$ formed a clearly detectable biofilm. The shortest period required for biofilm formation was three days, and the longest was six days. The average number of days until the biofilm was formed was 4.4 days \pm 0.90 , and the majority of the isolates $(75.9 \%)$ were able to form the biofilm in five days or less.

The differences on the average number of days until biofilm formation by Ophidian (5.1 days), Chelonian (4.7 days), and Saurian isolates (4.2 days) were considered not to have statistical significance $(p=0.211)$ (Table 4$)$.

\subsection{Minimum Biofilm Inhibitory Concentration and Minimum Biofilm Eradication Concentration Determination}

The minimum biofilm inhibitory concentration (MBIC) and minimum biofilm eradication concentration (MBEC) values of chlorhexidine gluconate regarding each isolate can be found on Supplementary Table S1.

The MBIC values ranged from $14.29 \mathrm{mg} / \mathrm{L}$ to $232.15 \mathrm{mg} / \mathrm{L}$, with an average value of $68.41 \mathrm{mg} / \mathrm{L} \pm 32.68$, and a median value of $71.43 \mathrm{mg} / \mathrm{L}$. Despite the broad range of values, $71.43 \mathrm{mg} / \mathrm{L}$ of chlorhexidine gluconate was the MBIC value for more than half (59.4\%) of the isolates tested. When comparing groups, the recorded average MBIC values regarding Ophidian, $57.15 \mathrm{mg} / \mathrm{L}$, Chelonian, $64.02 \mathrm{mg} / \mathrm{L}$, and Saurian isolates, $72.87 \mathrm{mg} / \mathrm{L}$, did not statistically differ $(p=0.509)$ (Table 4$)$. 
Concerning the MBEC values, the average chlorhexidine gluconate biofilm eradication concentration was $360.08 \mathrm{mg} / \mathrm{L} \pm 235.18$, with a minimum of $33.34 \mathrm{mg} / \mathrm{L}$ and a maximum of $714.29 \mathrm{mg} / \mathrm{L}$, and a median value of $392.86 \mathrm{mg} / \mathrm{L}$. Regarding six isolates, one Ophidian, one Chelonian, and four Saurian related isolates, the MBEC values were considered to be greater than the highest concentration tested, therefore, the results were expressed as $>714.29 \mathrm{mg} / \mathrm{L}$.

\section{Discussion}

Several research groups from multiple countries have reported the isolation of Salmonella spp. from pet or captive reptiles, including turtles, lizards, and snakes [26-32]. Although this is not a recent issue, to the author's best knowledge, the present report is the first regarding the isolation of Salmonella spp. from healthy pet reptiles in Portugal. Our results point out to an overall Salmonella spp. prevalence of $41 \%$, which is similar to studies performed with captive or pet reptiles in Australia (47\%) [32], Spain (48\%) [14], Norway (43\%) [33], or Sweden (49\%) [7], but higher than reports from smuggled reptiles in Taiwan (30.9\%) [15] or captive animals in Croatia (13\%) [29] or in New Zealand (11.4\%) [31]. Furthermore, in our study, the prevalence of Salmonella spp. was higher in both Ophidians $(50 \%)$ and Saurians $(51.9 \%)$, when compared with Chelonians $(20.9 \%)(p=0.016)$. The lower isolation rates in turtles when compared with other reptiles can be associated with seasonal variations, observed when turtles are preparing for hibernation [28], but also with the diet of these animals $[12,15,16]$. In fact, the sample collection period occurred before the hibernation stage of Chelonians, during the colder months of the year. Nevertheless, the impact of pet turtles in the reptile-associated salmonellosis scenario should not be underestimated, since exposure to Salmonella positive turtles has been linked to disease outbreaks [34-36].

High levels of antimicrobial susceptibility to the majority of the antibiotics tested were found in most the Salmonella isolates, and only three isolates $(9.37 \%)$ were resistant to three or more of the compounds tested. Our results differ from those reported in a recent study carried out in Spain, in which $72 \%$ of the isolates were considered to be multidrug resistant [14]. Salmonella isolates from reptiles are known to be resistant to several antibiotics frequently used in therapy. This not only implies that reptiles can shed multidrug resistant salmonellae to the environment and to other animals, including humans, but also the genes responsible for those antimicrobial resistances could be transferred to other enteric bacteria [17].

All the isolates studied expressed both hemolytic and lipolytic behaviors on plate tests. These two virulence phenotypes should be further investigated. Hemolysis is not associated with human non-typhoidal salmonellosis cases, and it has not been reported as a virulence trait by other authors, though it was shown that the hemolytic activity in Salmonella enterica serovar Typhimurium is dependent of the pathogenicity island 1 type III secretion system [37]. Extracellular lipases have been proposed as potential virulence factors in other pathogenic bacteria, such as Staphylococcus aureus, Staphylococcus epidermis, or Pseudomonas aeruginosa [38], though their role in Salmonella spp. virulence does not seem to be fully studied [39]. DNase testing pointed out the presence of extracellular desoxiribonucleases in more than half of the isolates. Gelatinase activity was not detected, even though it is a biochemical characteristic of Salmonella enterica subsp. arizonae [40]. It is possible that the analyzed isolates harbored the gene responsible for gelatin digestion, even though the isolates under the present study conditions did not express that phenotype. Recently, Salmonellae isolated from ready-to-eat shrimps were also found to express hemolytic, lipolytic, DNA degrading activity and also gelatinase production [41]. Additional studies are necessary in order to understand the extent of the possible role of these phenotypes both in animal and in human Salmonella infections. Actually, from the obtained data, the possibility of the same bacterial clone infecting different animals and adapting/evolving within the hosts cannot be excluded. Although a molecular based approach would bring valuable information regarding the identity and the possible genetic relationship between 
the studied isolates, the present report was designed to clarify the therapeutic potential of chlorhexidine, testing one isolate from each animal. Despite the possible genetic similarities, the foremost important assessed feature of each Salmonella isolate was the phenotypical behavior, namely the susceptibility to a commonly used biocide, chlorhexidine gluconate. Thus, the information resulting from this study can be adapted and applied in reptile medicine.

In the present study, the occurrence of both bactericidal and bacteriostatic effects of chlorhexidine gluconate is an example of the duality of the antimicrobial effect that takes place according to the applied concentration. Previous reports revealed chlorhexidine gluconate MIC values ranging from 8 to $16 \mathrm{mg} / \mathrm{L}$ when tested towards Salmonella Bredeney, Dublin, Gallinarum, Montivideo Virshow and Typhimurium [42]. Another study recorded a range of MIC values for Salmonella isolates of animal origin (broilers, cattle and pigs) between 2 and $64 \mathrm{mg} / \mathrm{L}$ [43]. More recent studies reported MIC values of 1-8 mg/L in turkey Salmonella isolates from commercial processing plants, and MIC values below $4 \mathrm{mg} / \mathrm{L}$ to $64 \mathrm{mg} / \mathrm{L}$ regarding different Salmonella serovars isolated from chicken and in egg production chains $[6,44,45]$. The overall mean MIC value calculated for the studied Salmonella spp. isolates from pet reptiles was $11.90 \mathrm{mg} / \mathrm{L}$, which is coherent with those values. The global mean MBC value is approximately three times the mean MIC. The suggestion that both MIC and MBC values should be included in the monitorization of biocidal susceptibility is consistent with the results obtained in this study considering that both values provide complementary information [46].

Although MIC an MBC values are valuable for evaluating the antimicrobial effect of chlorhexidine gluconate, the previous studies were carried out with planktonic cells. The fact that the Salmonella spp. isolates are capable of biofilm formation is worrisome, since Salmonella organized in biofilms is less susceptible to disinfectants than planktonic cells, with preliminary studies indicating that disinfectants used at an effective concentration for Salmonella biofilm reduction can cause the selection of more virulent cells [47]. The high frequency of the studied reptile Salmonella isolates capable of forming biofilms $(90.63 \%)$ is similar to previously reported data. High frequencies of pellicle formation in the airliquid interface by Salmonella Agona (100\%), Salmonella Montevideo (100\%), and Salmonella Senftenberg (88\%) were already described [48]. However, in the same study, only 55\% of the Salmonella Typhimurium isolates tested were biofilm producers [48]. On other studies, the expression of biofilm formation by Salmonella Typhimurium isolates varied under the same circumstances, with different strains and morphotypes demonstrating different biofilm capabilities [49,50].

Biofilms are common on liquid-hard surfaces interfaces [51], such as in certain type of reptile cages or in aquariums. In order to simulate a more realistic approach to the effects of chlorhexidine gluconate on Salmonella cultures, the antimicrobial action of chlorhexidine gluconate activity was tested on the biofilms formed by the reptile Salmonella isolates during a 24 h-period. A chlorhexidine gluconate MBIC value within the concentration limits tested was obtained regarding all the Salmonella isolates studied. Regarding the Salmonella isolates towards which the MBEC values exceeded $714.29 \mathrm{mg} / \mathrm{L}$, chlorhexidine gluconate was simply not effective in terms of eradicating those biofilms. Overall, chlorhexidine gluconate MBIC and MBEC results show that Salmonella biofilms are less susceptible to this biocide, what is consistent with a previous report which stated that three-day old Salmonella Typhimurium biofilms were less susceptible to chlorhexidine gluconate when compared to the corresponding planktonic cells [52].

\section{Materials and Methods}

\subsection{Sample Collection and Salmonella spp. Isolation}

A total of 78 cloacal swabs were obtained from pet reptiles, specifically 43 Chelonians (commonly referred as turtles), 27 Saurians (commonly named lizards), and eight Ophidians (usually known as snakes). The cloacal swabs were performed using cotton swabs in AMIES transport media (VWR, Amadora, Portugal) during rou- 
tine health check-ups at the house of the owners or at pet shops, all located in the Lisbon Metropolitan Area, Portugal. All animals were cared for according to the rules given by the current EU (Directive 2010/63/EC) and national (DL 113/2013) legislation and by the competent authority (Direção Geral de Alimentação e Veterinária, DGAV, (www.dgv.min-agricultura.pt/portal/page/portal/DGV, accessed on 20 January 2021) in Portugal. Verbal informed consent was obtained from all the owners. Trained veterinarians performed sample collection of all the samples, following standard routine procedures. After collection, swabs were kept under refrigeration conditions $\left(4{ }^{\circ} \mathrm{C}\right)$ for no longer than $48 \mathrm{~h}$ until processing in the Microbiology Laboratory of the Veterinary Medicine Faculty-University of Lisbon for Salmonella spp. isolation.

Briefly, each cloacal swab was homogenized and incubated in $5 \mathrm{~mL}$ of buffered peptone water (BPW) (Scharlau, Valencia, Spain) for $18 \pm 2 \mathrm{~h}$ at $37^{\circ} \mathrm{C}$. After the initial incubation, $1 \mathrm{~mL}$ of BPW was then added to $10 \mathrm{~mL}$ of Muller-Kaufmann Tetrathionate (MKTT) Broth (Oxoid, Hampshire, UK) and incubated for $18-24 \mathrm{~h}$ at $37^{\circ} \mathrm{C}$. Simultaneously, $0.1 \mathrm{~mL}$ of the BPW solution was added to $10 \mathrm{~mL}$ Rappaport-Vassiliadis broth (Oxoid, Hampshire, England) and the resulting suspension was incubated for $18-24 \mathrm{~h}$ at $41.5^{\circ} \mathrm{C}$. Afterwards, suspensions were inoculated in Hektoen Agar (Liofilchem, Teramo, Italy) and xylose lysine deoxicholate agar (Scharlau, Valencia, Spain) plates, by streaking, and incubated at $37^{\circ} \mathrm{C}$ for $20 \pm 2 \mathrm{~h}$. The resulting presumptive Salmonella spp. colonies were selected and transferred to triple sugar iron (TSI) Agar (Scharlau, Valencia, Spain) and to urea broth (Oxoid, Dadirlly, France) and incubated for $20 \pm 2 \mathrm{~h}$ at $37^{\circ} \mathrm{C}$. Presumptive Salmonella spp. isolates were identified through the growth pattern in TSI agar and in Urea Broth. The method described is an adaptation of a previously described method [53]. Salmonella spp. isolates were identified using biochemical profile system API 20E (BioMérieux, Craponne, France). The biochemical identification was later confirmed by agglutination with Antiserum Salmonella OMNIVALENT Omni-O (Bio-Rad Laboratories, Inc., Marnes-la-Coquette, France).

\subsection{Antimicrobial Susceptibility Testing}

Antimicrobial susceptibility testing was performed by the disk diffusion method, according to Clinical and Laboratory Standards Institute guidelines (CLSI) [54]. The tested antibiotics were amoxicillin/clavulanic acid (AMC, $30 \mu \mathrm{g})$, ampicillin (AMP, $10 \mu \mathrm{g}$ ), amikacin (AK, $30 \mu \mathrm{g})$, chloramphenicol (C, $30 \mu \mathrm{g})$, gentamicin $(\mathrm{CN}, 10 \mu \mathrm{g})$, cefotaxime (CTX, $30 \mu \mathrm{g})$, enrofloxacin (ENR, $5 \mu \mathrm{g}$ ), nalidixic acid (NA, $30 \mu \mathrm{g}$ ), penicillin (P, $10 \mathrm{U})$, ciprofloxacin (CIP, $5 \mu \mathrm{g}$ ), sulfamethoxazole/trimethoprim (SXT, $25 \mu \mathrm{g}$ ), and tetracycline (TE, $30 \mu \mathrm{g})$. All antibiotics were purchased from Oxoid, Dadirlly, France. Escherichia coli ATCC 25922 was used as the control strain for test performance. Multidrug resistance (MDR) phenotype was considered to be present whenever an isolate revealed resistance to three or more antimicrobial compounds belonging to different classes [55].

\subsection{Virulence Phenotype Analysis}

In order to assess the virulence phenotype of the Salmonella isolates, plate tests were performed for evaluating their DNase, gelatinase, hemolytic and lipase activities.

DNase activity testing was performed by streaking the bacterial isolates on DNase test Agar plates (Liofilchem, Teramo, Italy) supplemented with $0.01 \%$ toluidine blue. The plates were incubated for $48 \mathrm{~h}$ at $37^{\circ} \mathrm{C}$ and positive results showed a transparent halo surrounding the colonies.

Gelatinase activity was tested by streaking the isolates on Gelatinase test Agar plates (Liofilchem, Teramo, Italy), followed by incubation at $37^{\circ} \mathrm{C}$ for $48 \mathrm{~h}$. Afterwards, plates were flooded with a mercury chloride solution and the gelatinase positive isolates showed a transparent halo around the colonies.

Production of hemolysins was determined by streaking the isolates on Columbia Agar plates supplemented with 5\% sheep blood (BioMérieux, Craponne, France) and incubated for $48 \mathrm{~h}$ at $37^{\circ} \mathrm{C}$. The presence of clear halos surrounding the colonies was interpreted as $\beta$-hemolysis. 
Lipase activity testing was achieved by culturing the isolates in Spirit Blue Agar plates (Difco, Algés, Portugal) supplemented with Tween $80(30 \mathrm{~g} / \mathrm{L})$ and incubating for $48 \mathrm{~h}$ at $37^{\circ} \mathrm{C}$. Lipase producing isolates exhibited clear halos around the colonies.

\subsection{Chlorhexidine Gluconate Minimum Inhibitory Concentration and Minimum Bactericidal Concentration Determination}

The in vitro susceptibility profile of the Salmonella isolates to chlorhexidine gluconate was assessed by an adapted protocol based on the microtiter broth dilution method $[56,57]$. Isolates were grown in a nonselective brain heart infusion (BHI) agar medium (VWR Chemicals, Leuven, Belgium) at $37^{\circ} \mathrm{C}$ for $24 \mathrm{~h}$. Bacterial suspensions with $10^{8} \mathrm{CFU} / \mathrm{mL}$ were prepared directly from plate cultures in sterile normal saline (Merck, Germany) to a 0.5 McFarland suspension. The bacterial suspensions were then diluted in fresh BHI broth (VWR Chemicals, Leuven, Belgium) to a concentration of $10^{7} \mathrm{CFU} / \mathrm{mL}$.

Chlorhexidine gluconate dilutions were prepared from a stock solution at a concentration of $4 \%(w / v)$ (AGA, Lisboa, Portugal). A volume of $25 \mu \mathrm{L}$ of chlorhexidine gluconate at $0.5,0.1,0.05,0.01,0.005$ and $0.001 \%$ were distributed in 96-well flat-bottomed polystyrene microtiter plates (Nunc, Thermo Fisher Scientific, Roskilde, Denmark), apart from the negative and positive controls. All the wells were inoculated with $150 \mu \mathrm{L}$ of the $10^{7} \mathrm{CFU} / \mathrm{mL}$ bacterial suspensions, with exception of the negative control wells, which contained only broth medium. Therefore, the final concentration of chlorhexidine gluconate in the wells corresponded to $714.28,142.86,71.43,14.29,7.14$, and $1.43 \mathrm{mg} / \mathrm{L}$. Afterwards, microplates were statically incubated for $24 \mathrm{~h}$ at $37^{\circ} \mathrm{C}$. The minimum inhibitory concentration (MIC) was determined as the lowest concentration of chlorhexidine gluconate that visually inhibited microbial growth.

The minimum bactericidal concentration (MBC) value was assessed by inoculating $3 \mu \mathrm{L}$ of the suspensions from the wells were no growth was observed on BHI agar plates, which were incubated at $37^{\circ} \mathrm{C}$ for $24 \mathrm{~h}$. MBC was determined as the lowest chlorhexidine gluconate concentration that did not allow colony development $[57,58]$.

The ratio between MBC and MIC was calculated in order to determine the antimicrobial effect of chlorhexidine gluconate. The effect was considered to be bactericidal when the MBC was no more than fourfold the MIC, or bacteriostatic when the ratio exceeded four [58].

All experiments were conducted in duplicate and independent assays were performed at least three times in different dates.

\subsection{Biofilm Formation in the Air-Liquid Interface}

Biofilm forming ability was assessed through a biofilm formation assay in the airliquid interface, by inoculating $0.5 \mathrm{~mL}$ of an overnight $\mathrm{BHI}$ broth culture, adjusted to a $0.5 \mathrm{McF}$ arland standard, in a $4.5 \mathrm{~mL}$ of Luria broth (LB) without $\mathrm{NaCl}(1: 10)$, prepared using yeast extract (Oxoid, Hampshire, England) and bacto tryptone (BD, Oeiras, Portugal). Isolates were incubated at $28^{\circ} \mathrm{C}$ for eight days and each isolate was visually examined for pellicle formation on a daily basis [49]. The isolates capable of forming a pellicle in two distinct occasions were considered to be positive for biofilm formation, and the number of days required until the pellicle was perceivable was used to calculate the mean time for biofilm formation.

All assays were repeated in three independent dates, including $10 \%$ replicates.

\subsection{Chlorhexidine Gluconate Minimum Biofilm Inhibitory Concentration and Minimum Biofilm Eradication Concentration Determination}

The antimicrobial susceptibility of the Salmonella isolates when embedded in a $24 \mathrm{~h}$ biofilm was evaluated by a modified version of the Calgary Biofilm Pin Lid Device [57,59]. For minimum biofilm inhibitory concentration (MBIC) and minimum biofilm eradication concentration (MBEC) assays, the bacterial isolates were grown in $\mathrm{BHI}$ agar medium (VWR Chemicals, Leuven, Belgium) at $37^{\circ} \mathrm{C}$ for $24 \mathrm{~h}$. Bacterial suspensions with approximately $10^{8} \mathrm{CFU} / \mathrm{mL}$ were prepared directly from plate cultures in sterile normal saline 
(Merck, Darmstadt, Germany) by comparison with a 0.5 McFarland standard (BioMérieux, Craponne, France). Suspensions were then diluted in fresh BHI broth (VWR Chemicals, Leuven, Belgium) to a concentration of $10^{6} \mathrm{CFU} / \mathrm{mL}$. Then, $175 \mu \mathrm{L}$ of the bacterial suspensions were distributed in 96-well flat-bottomed polystyrene microtiter plates, covered with 96-peg polystyrene lids (Nunc-TSP; Thermo Fisher Scientific, Roskilde, Denmark) and statically incubated for $24 \mathrm{~h}$ at $37^{\circ} \mathrm{C}$, allowing biofilm formation on the pegs. Peg lids were then rinsed three times in sterile normal saline to remove planktonic bacteria and placed on new microplates containing the set of chlorhexidine gluconate solutions previously described, corresponding to a final concentration by well of $714.28,142.86,71.43,14.29$, 7.14 , and $1.43 \mathrm{mg} / \mathrm{L}$.

Microplates were again incubated for $24 \mathrm{~h}$ at $37^{\circ} \mathrm{C}$, without shaking. After incubation, peg lids were removed, and the MBIC value was determined as the lowest chlorhexidine gluconate concentration that visually inhibited microbial growth. Subsequently, in order to determine the MBEC value, peg lids were rinsed three times in sterile normal saline, placed in new microplates containing only $175 \mu \mathrm{L}$ of fresh BHI medium and incubated in an ultrasound bath (Grant MXB14, Essex, England), at $50 \mathrm{~Hz}$ during $15 \mathrm{~min}$ in order to disperse the biofilm-based bacteria from the peg surface. Afterwards, peg lids were discarded, and microplates were covered with normal lids and incubated for $24 \mathrm{~h}$ at $37^{\circ} \mathrm{C}$. The MBEC value was determined through direct observation of bacterial growth in the wells and defined as the lowest chlorhexidine gluconate concentration that visually eliminates the microbial growth [57].

Experiments were conducted in duplicate and independent assays were performed at least two times on different dates.

\subsection{Statistical Analysis}

For statistical analysis, the associations between frequency of Salmonella isolation and reptile group, AMR Salmonella and reptile group and virulence phenotype and reptile group were evaluated using the Fisher exact test. Association between different MIC, MEC and MBIC values of chlorhexidine gluconate on Salmonella isolates, the number of days until biofilm formation and the reptiles group was assessed recurring to the Brown-Forsythe robustness test based on a one-way ANOVA test. All statistical tests were performed on IBM SPSS Statistical program version 26 for Windows (SPSS Inc., Chicago, IL, USA). Associations were considered to be significant whenever $P$ values were less than 0.05 .

\section{Conclusions}

The present study reports the isolation of Salmonella from healthy pet reptiles and stresses their possible role in human non-typhoidal salmonellosis cases. Although presenting high levels of antimicrobial susceptibility, the expression of phenotypical virulence traits and the ability to form biofilms by these isolates are worrisome. Pet reptile owners should always employ good hygiene practices whenever manipulating the animals, but also when in contact with the environment in which the animals are kept. Overall, the use of chlorhexidine gluconate was considered to be effective, both in planktonic cells and biofilms, pointing out the potential of this biocide's use in reptile clinics.

Supplementary Materials: The following are available online at https:/ / www.mdpi.com/2079-638 2/10/3/324/s1, Table S1: Detailed information regarding the studied Salmonella isolates and the results of Antimicrobial Susceptibility analysis, Virulence Phenotype analysis, Minimum Inhibitory Concentration, Minimum Bactericidal Concentration, Minimum Biofilm Inhibitory Concentration and Minimum Biofilm Eradication Concentration Determination and Biofilm Formation.

Author Contributions: Conceptualization: F.B. and M.O.; methodology: A.C.C., I.D. and A.R.; software: J.B.C.; formal analysis: A.C.C., I.D. and J.B.C.; writing-original draft preparation: J.B.C.; writing-review and editing: J.B.C., F.B. and M.O.; supervision: M.O.; funding acquisition: F.B. and M.O. All authors have read and agreed to the published version of the manuscript. 
Funding: This research was supported by CIISA-Centro de Investigação Interdisciplinar em Sanidade Animal, Faculdade de Medicina Veterinária, Universidade de Lisboa, Project UIDB/00276/ 2020 (funded by FCT—Fundação para a Ciência e Tecnologia IP).

Institutional Review Board Statement: Not applicable.

Informed Consent Statement: Informed consent was obtained from all subjects involved in the study.

Data Availability Statement: The data presented in this study are available in Supplementary Table S1.

Conflicts of Interest: The authors declare no conflict of interest.

\section{References}

1. European Food Safety Authority and European Centre for Disease Prevention and Control (EFSA and ECDC). The European Union One Health 2018 Zoonoses Report. EFSA J. 2019, 17, 5926. [CrossRef]

2. Majowicz, S.E.; Musto, J.; Scallan, E.; Angulo, F.J; Kirk, M.; O’Brien, S.J.; Jones, T.F.; Fazil, A.; Hoekstra, R.M. The global burden of nontyphoidal salmonella gastroenteritis. Clin. Infect. Dis. 2010, 50, 882-889. [CrossRef]

3. Crum-Cianflone, N.F. Salmonellosis and the gastrointestinal tract: More than just peanut butter. Curr. Gastroenterol. Rep. 2008, 10, 424-431. [CrossRef]

4. Van Duijkeren, E.; Houwers, D.J. A critical assessment of antimicrobial treatment in uncomplicated Salmonella enteritis. Vet. Microbiol. 2000, 73, 61-73. [CrossRef]

5. FEDIAF (The European Pet Food Industry). FEDIAF Annual Report 2019; FEDIAF: Bruxelles, Belgium, 2020.

6. Hoelzer, K.; Moreno Switt, A.; Wiedmann, M.; Majowicz, S.; Musto, J.; Scallan, E.; Angulo, F.; Kirk, M.; O’Brien, S.; Jones, T.; et al. Animal contact as a source of human non-typhoidal salmonellosis. Vet. Res. 2011, 42, 34. [CrossRef]

7. Wikström, V.O.; Fernström, L.L.; Melin, L.; Boqvist, S. Salmonella isolated from individual reptiles and environmental samples from terraria in private households in Sweden. Acta Vet. Scand. 2014, 56, 7. [CrossRef]

8. Brenner, F.W.; Villar, R.G.; Angulo, F.J.; Tauxe, R.; Swaminathan, B. Salmonella nomenclature. J. Clin. Microbiol. 2000, 38, 2465-2467. [CrossRef] [PubMed]

9. Mermin, J.; Hutwagner, L.; Vugia, D.; Shallow, S.; Daily, P.; Bender, J.; Koehler, J.; Marcus, R.; Angulo, F.J. Reptiles, amphibians, and human Salmonella infection: A population-based, case-control study. Clin. Infect. Dis. 2004, 38. [CrossRef] [PubMed]

10. Corrente, M.; Sangiorgio, G.; Grandolfo, E.; Bodnar, L.; Catella, C.; Trotta, A.; Martella, V.; Buonavoglia, D. Risk for zoonotic Salmonella transmission from pet reptiles: A survey on knowledge, attitudes and practices of reptile-owners related to reptile husbandry. Prev. Vet. Med. 2017, 146, 73-78. [CrossRef] [PubMed]

11. Whiley, H.; Gardner, M.G.; Ross, K. A review of salmonella and squamates (Lizards, snakes and amphisbians): Implications for public health. Pathogens 2017, 6, 38. [CrossRef]

12. Sodagari, H.R.; Habib, I.; Shahabi, M.P.; Dybing, N.A.; Wang, P.; Bruce, M. A review of the public health challenges of salmonella and turtles. Vet. Sci. 2020, 7, 56. [CrossRef]

13. Bertrand, S.; Rimhanen-Finne, R.; Weill, F.X.; Rabsch, W.; Thornton, L.; Perevoscikovs, J.; van Pelt, W.; Heck, M. Salmonella infections associated with reptiles: The current situation in Europe. Eur. Surveill. 2008, 13, 18902. [CrossRef]

14. Marin, C.; Lorenzo-Rebenaque, L.; Laso, O.; Villora-Gonzalez, J.; Vega, S. Pet Reptiles: A Potential Source of Transmission of Multidrug-Resistant Salmonella. Front. Vet. Sci. 2021, 7. [CrossRef] [PubMed]

15. Chen, C.Y.; Chen, W.C.; Chin, S.C.; Lai, Y.H.; Tung, K.C.; Chiou, C.S.; Hsu, Y.M.; Chang, C.C. Prevalence and antimicrobial susceptibility of salmonellae isolates from reptiles in Taiwan. J. Vet. Diagn. Investig. 2010, 22, 44-50. [CrossRef]

16. Sylvester, W.R.B.; Amadi, V.; Pinckney, R.; Macpherson, C.N.L.; Mckibben, J.S.; Bruhl-Day, R.; Johnson, R.; Hariharan, H. Prevalence, Serovars and Antimicrobial Susceptibility of Salmonella spp. from Wild and Domestic Green Iguanas (Iguana iguana) in Grenada, West Indies. Zoonoses Public Health 2014, 61, 436-441. [CrossRef]

17. Ebani, V.V. Domestic reptiles as source of zoonotic bacteria: A mini review. Asian Pac. J. Trop. Med. 2017, 10, 723-728. [CrossRef]

18. Reygaert, W.C. An overview of the antimicrobial resistance mechanisms of bacteria. AIMS Microbiol. 2018, 4, 482-501. [CrossRef]

19. Bertelloni, F.; Chemaly, M.; Cerri, D.; Le Gall, F.; Ebani, V.V. Salmonella infection in healthy pet reptiles: Bacteriological isolation and study of some pathogenic characters. Acta Microbiol. Immunol. Hung. 2016, 63, 203-216. [CrossRef]

20. Xia, Y.; Li, H.; Shen, Y. Antimicrobial Drug Resistance in Salmonella enteritidis Isolated from Edible Snakes with Pneumonia and Its Pathogenicity in Chickens. Front. Vet. Sci. 2020, 7, 463. [CrossRef]

21. Steenackers, H.; Hermans, K.; Vanderleyden, J.; De Keersmaecker, S.C.J. Salmonella biofilms: An overview on occurrence, structure, regulation and eradication. Food Res. Int. 2012, 45, 502-531. [CrossRef]

22. Trampari, E.; Holden, E.R.; Wickham, G.J.; Ravi, A.; de Martins, L.O.; Savva, G.M.; Webber, M.A. Exposure of Salmonella biofilms to antibiotic concentrations rapidly selects resistance with collateral tradeoffs. NPJ Biofilms Microbiomes 2021, 7, 1-13. [CrossRef]

23. Mcdonnell, G.; Russell, A.D. Antiseptics and disinfectants: Activity, action, and resistance. Clin. Microbiol. Rev. 1999, 12, 147-179. [CrossRef]

24. Main, R.C. Should chlorhexidine gluconate be used in wound cleansing? J. Wound Care 2008, 17, 112-114. [CrossRef] 
25. O'Rourke, D.P.; Cox, J.D.; Baumann, D.P. Nontraditional Species. In Management of Animal Care and Use Programs in Research, Education, and Testing; CRC Press: Boca Raton, FL, USA, 2020; pp. 579-596.

26. Corrente, M.; Madio, A.; Friedrich, K.G.; Greco, G.; Desario, C.; Tagliabue, S.; D’Incau, M.; Campolo, M.; Buonavoglia, C. Isolation of Salmonella strains from reptile faeces and comparison of different culture media. J. Appl. Microbiol. 2004, 96, 709-715. [CrossRef]

27. Back, D.-S.; Shin, G.-W.; Wendt, M.; Heo, G.-J. Prevalence of Salmonella spp. in pet turtles and their environment. Lab. Anim. Res. 2016, 32, 166. [CrossRef]

28. Geue, L.; Löschner, U. Salmonella enterica in reptiles of German and Austrian origin. Vet. Microbiol. 2002, 84, 79-91. [CrossRef]

29. Lukac, M.; Pedersen, K.; Prukner-Radovcic, E. Prevalence of salmonella in captive reptiles from Croatia. J. Zoo Wildl. Med. 2015, 46, 234-240. [CrossRef]

30. Pedersen, K.; Lassen-Nielsen, A.-M.; Nordentoft, S.; Hammer, A.S. Serovars of Salmonella from captive reptiles. Zoonoses Public Health 2009, 56, 238-242. [CrossRef] [PubMed]

31. Kikillus, K.; Gartrell, B.; Motion, E. Prevalence of Salmonella spp., and serovars isolated from captive exotic reptiles in New Zealand. N. Z. Vet. J. 2011, 59, 174-178. [CrossRef] [PubMed]

32. Scheelings, T.F.; Lightfoot, D.; Holz, P. Prevalence of salmonella in australian reptiles. J. Wildl. Dis. 2011, 47, 1-11. [CrossRef]

33. Bjelland, A.M.; Sandvik, L.M.; Skarstein, M.M.; Svendal, L.; Debenham, J.J. Prevalence of Salmonella serovars isolated from reptiles in Norwegian zoos. Acta Vet. Scand. 2020, 62. [CrossRef]

34. Weltman, A.; Smee, A.; Moll, M.; Deasy, M.; Pringle, J.; Williams, I.; Behravesh, C.B.; Wright, J.; Routh, J.; Longenberger, A. Notes from the field: Outbreak of salmonellosis associated with pet turtle exposures-United States, 2011. Morb. Mortal. Wkly Rep. 2012, 61,79 .

35. Gambino-Shirley, K.; Stevenson, L.; Wargo, K.; Burnworth, L.; Roberts, J.; Garrett, N.; Van Duyne, S.; McAllister, G.; Nichols, M. Notes from the Field: Four Multistate Outbreaks of Human Salmonella Infections Linked to Small Turtle Exposure-United States, 2015. MMWR. Morb. Mortal. Wkly. Rep. 2016, 65, 655-656. [CrossRef]

36. Basler, C.; Bottichio, L.; Higa, J.; Prado, B.; Wong, M.; Bosch, S. Multistate Outbreak of Human Salmonella Poona Infections Associated with Pet Turtle Exposure-United States, 2014. MMWR. Morb. Mortal. Wkly. Rep. 2015, 64, 804. [CrossRef]

37. Miki, T.; Okada, N.; Shimada, Y.; Danbara, H. Characterization of Salmonella pathogenicity island 1 type III secretion-dependent hemolytic activity in Salmonella enterica serovar Typhimurium. Microb. Pathog. 2004, 37, 65-72. [CrossRef]

38. Pascoal, A.; Estevinho, L.M.; Martins, I.M.; Choupina, A.B. REVIEW: Novel sources and functions of microbial lipases and their role in the infection mechanisms. Physiol. Mol. Plant Pathol. 2018. [CrossRef]

39. Bender, J.; Flieger, A. Lipases as Pathogenicity Factors of Bacterial Pathogens of Humans. In Handbook of Hydrocarbon and Lipid Microbiology; Springer: Berlin/Heidelberg, Germany, 2010; pp. 3241-3258.

40. Lamas, A.; Miranda, J.M.; Regal, P.; Vázquez, B.; Franco, C.M.; Cepeda, A. A comprehensive review of non-enterica subspecies of Salmonella enterica. Microbiol. Res. 2018, 206, 60-73. [CrossRef]

41. Beshiru, A.; Igbinosa, I.H.; Igbinosa, E.O. Biofilm formation and potential virulence factors of Salmonella strains isolated from ready-to-eat shrimps. PLOS ONE 2018, 13. [CrossRef]

42. Denton, G.W. Chlorhexidine. In Disinfection, Sterilization and Preservation; Block, S.S., Ed.; Lippincott Williams \& Wilkins: Philadelphia, PA, USA, 2001; pp. 325-333.

43. Aarestrup, F.M.; Hasman, H. Susceptibility of different bacterial species isolated from food animals to copper sulphate, zinc chloride and antimicrobial substances used for disinfection. Vet. Microbiol. 2004, 100, 83-89. [CrossRef]

44. Beier, R.C.; Anderson, P.N.; Hume, M.E.; Poole, T.L.; Duke, S.E.; Crippen, T.L.; Sheffield, C.L.; Caldwell, D.J.; Byrd, J.A.; Anderson, R.C.; et al. Characterization of salmonella enterica isolates from Turkeys in commercial processing plants for resistance to antibiotics, disinfectants, and a growth promoter. Foodborne Pathog. Dis. 2011, 8, 593-600. [CrossRef]

45. Long, M.; Lai, H.; Deng, W.; Zhou, K.; Li, B.; Liu, S.; Fan, L.; Wang, H.; Zou, L. Disinfectant susceptibility of different Salmonella serotypes isolated from chicken and egg production chains. J. Appl. Microbiol. 2016, 121, 672-681. [CrossRef]

46. Maillard, J.Y.; Bloomfield, S.; Coelho, J.R.; Collier, P.; Cookson, B.; Fanning, S.; Hill, A.; Hartemann, P.; McBain, A.J.; Oggioni, M.; et al. Does microbicide use in consumer products promote antimicrobial resistance? A critical review and recommendations for a cohesive approach to risk assessment. Microb. Drug Resist. 2013, 19, 344-354. [CrossRef] [PubMed]

47. Rodrigues, D.; Cerca, N.; Teixeira, P.; Oliveira, R.; Ceri, H.; Azeredo, J. Listeria monocytogenes and Salmonella enterica Enteritidis biofilms susceptibility to different disinfectants and stress-response and virulence gene expression of surviving cells. Microb. Drug Resist. 2011, 17, 181-189. [CrossRef]

48. Vestby, L.K.; Møretrø, T.; Langsrud, S.; Heir, E.; Nesse, L.L. Biofilm forming abilities of Salmonella are correlated with persistence in fish meal- and feed factories. BMC Vet. Res. 2009, 5, 1-6. [CrossRef] [PubMed]

49. Seixas, R.; Machado, J.; Bernardo, F.; Vilela, C.; Oliveira, M. Biofilm formation by salmonella enterica serovar 1,4,[5],12:i:portuguese isolates: A phenotypic, genotypic, and socio-geographic analysis. Curr. Microbiol. 2014, 68, 670-677. [CrossRef] [PubMed]

50. Ramachandran, G.; Aheto, K.; Shirtliff, M.E.; Tennant, S.M. Poor biofilm-forming ability and long-term survival of invasive Salmonella Typhimurium ST313. Pathog. Dis. 2016, 74. [CrossRef] 
51. Otter, J.A.; Vickery, K.; Walker, J.T.; deLancey Pulcini, E.; Stoodley, P.; Goldenberg, S.D.; Salkeld, J.A.G.; Chewins, J.; Yezli, S.; Edgeworth, J.D. Surface-attached cells, biofilms and biocide susceptibility: Implications for hospital cleaning anddisinfection. J. Hosp. Infect. 2015, 89, 16-27. [CrossRef]

52. Wong, H.S.; Townsend, K.M.; Fenwick, S.G.; Trengove, R.D.; O'Handley, R.M. Comparative susceptibility of planktonic and 3-day-old Salmonella Typhimurium biofilms to disinfectants. J. Appl. Microbiol. 2010, 108, 2222-2228. [CrossRef]

53. Hendriksen, R.S. Laboratory Protocols Level 1: Training Course Isolation of Salmonella. In A Global Salmonella Surveillance and Laboratory. Support Project of the World Health Organization, 4th ed.; WHO: Geneva, Switzerland, 2003.

54. CLSI. Performance Standarts for Antimicrobial Susceptibility Testing; 25th Informational Supplement; CLSI=NCCLS M100-S25; CLSI: Wayne, PA, USA, 2015.

55. Magiorakos, A.-P.; Srinivasan, A.; Carey, R.B.; Carmeli, Y.; Falagas, M.E.; Giske, C.G.; Harbarth, S.; Hindler, J.F.; Kahlmeter, G.; Olsson-Liljequist, B.; et al. Multidrug-resistant, extensively drug-resistant and pandrug-resistant bacteria: An international expert proposal for interim standard definitions for acquired resistance. Clin. Microbiol. Infect. 2012, 18, 268-281. [CrossRef]

56. Wiegand, I.; Hilpert, K.; Hancock, R.E.W. Agar and broth dilution methods to determine the minimal inhibitory concentration (MIC) of antimicrobial substances. Nat. Protoc. 2008, 3, 163-175. [CrossRef]

57. Santos, R.; Gomes, D.; Macedo, H.; Barros, D.; Tibério, C.; Veiga, A.S.; Tavares, L.; Castanho, M.; Oliveira, M. Guar gum as a new antimicrobial peptide delivery system against diabetic foot ulcers Staphylococcus aureus isolates. J. Med. Microbiol. 2016, 65, 1092-1099. [CrossRef] [PubMed]

58. French, G.L. Bactericidal agents in the treatment of MRSA infections-The potential role of daptomycin. J. Antimicrob. Chemother. 2006, 58, 1107-1117. [CrossRef] [PubMed]

59. Ceri, H.; Olson, M.E.; Stremick, C.; Read, R.R.; Morck, D.; Buret, A. The Calgary Biofilm Device: New technology for rapid determination of antibiotic susceptibilities of bacterial biofilms. J. Clin. Microbiol. 1999, 37, 1771-1776. [CrossRef] [PubMed] 